\title{
ANÁLISE MORFOMÉTRICA DA BACIA HIDROGRÁFICA DO CÓRREGO MANHUAÇUZINHO, MINAS GERAIS
}

Andressa Rosa Mesquita1; Renata Paulo Macedo²; Monique Sabioni Lopes²; Thiago Delgado de Souza ${ }^{3}$; Sheila Elisângela Menini ${ }^{4}$

\begin{abstract}
${ }^{1}$ Mestranda do Programa de Pós Graduação em Engenharia Civil / Centro de Ciências Exatas, Universidade Federal de Viçosa (andressa.mesquita@ufv.br)

${ }^{2}$ Mestranda do Programa de Pós Graduação em Ciência Florestal / Centro de

Ciências Agrárias, Universidade Federal de Viçosa

${ }^{3}$ Mestrando do Programa de Pós Graduação em Engenharia de Transportes, Instituto Militar de Engenharia

${ }^{4}$ Doutoranda do Programa de Pós Graduação em Engenharia Civil / Centro de Ciências Exatas, Universidade Federal de Viçosa
\end{abstract}

Recebido em: 08/04/2017 - Aprovado em: 10/06/2017 - Publicado em: 20/06/2017 DOI: 10.18677/EnciBio_2017A4

\section{RESUMO}

O aumento da interferência do homem no meio ambiente provoca mudanças que afetam a dinâmica da água presente nas bacias hidrográficas. Dessa forma, a qualidade e a capacidade de infiltração da água no solo são reduzidas. As análises morfométricas de bacias hidrográficas fornecem parâmetros da rede de drenagem, além de limites e detalhes da topografia, o que possibilita planejar medidas de conservação da água. O Sistema de Informação Geográfica é de fundamental importância na caracterização automática da morfometria das bacias. O estudo objetiva descrever as características morfométricas da bacia hidrográfica do Córrego Manhuaçuzinho e fornecer informações para o gerenciamento dos recursos hídricos. O software utilizado na delimitação da bacia foi o ArcGIS 10.3.1; as cartas do IBGE foram referência para sua localização e os parâmetros morfométricos foram utilizados para sua caracterização. A bacia de Manhuaçuzinho foi classificada como alongada, fato que diminui o risco de enchentes. Sua ordem é 5 com padrão de drenagem predominante dendrítico, possui declividade média de $20,90 \%$ e apresenta elevada variação de altitude, com valores entre 731 e 1630 m. A partir dos estudos morfométricos realizados conclui-se que a bacia possui características propícias para o armazenamento de água da barragem, mas a grande amplitude altimétrica favorece o escoamento superficial, por isso são necessárias medidas que intensifiquem os processos de infiltração.

PALAVRAS-CHAVE: bacia hidrográfica, morfometria, Sistema de Informação Geográfica 


\title{
MORPHOMETRIC ANALYSIS OF THE MANHUAÇUZINHO STREAM HYDROGRAPHIC BASIN, MINAS GERAIS
}

\begin{abstract}
The increased human interference in the environment causes changes that affect the dynamics of water present in watershed. In this way, the quality and the capacity of infiltration of the water in the soil are reduced. The morphometric analyzes of the basins provide parameters of the drainage network, as well as the limits and details of the topography, which makes it possible to plan water conservation measures. The Geographic Information System is of fundamental importance in the automatic characterization of watershed morphometry. This study aims to describe the morphometric characteristics of the Corrego Manhuaçuzinho watershed and to provide information for the management of water resources. The software used in the delimitation of the basin was ArcGIS 10.3.1; the IBGE charts were reference for her location and the morphometric parameters were used to characterize the watershed. The Manhuaçuzinho basin was classified as elongated, a fact that reduces the risk of flooding. Its order is 5 with predominant dendritic drainage pattern, has a mean slope of $20.90 \%$ and presents high altitude variation, with values ranging from 731 to 1630 $\mathrm{m}$. From the morphometric studies carried out, it was concluded that the basin has characteristics that are conducive to the storage of water from the dam, but the high altimetric range favors surface flow, so that measures are necessary to intensify the infiltration processes.
\end{abstract}

KEYWORDS: watershed, morphometry, Geographic Information System

\section{INTRODUÇÃO}

A crescente interferência do homem no meio ambiente e a utilização inadequada do solo prejudicam a sustentabilidade dos recursos naturais. $O$ aumento populacional motivou a substituição de florestas nativas por outras culturas, principalmente as agrícolas (BERTOSSI et al., 2016; DIAS et al., 2016). Os impactos ambientais provocados pelos desmatamentos, exposição do solo às intempéries e a intensa utilização de insumos geram consequências negativas, como o escoamento superficial e a erosão (SANTOS et al., 2012). Essas mudanças afetam diretamente a dinâmica da água nas bacias hidrográficas. O uso inapropriado do solo degrada a superfície do terreno (RAMOS et al., 2014; BERTOL et al., 2015), diminui a sua capacidade de infiltração e reduz a qualidade da água (DESSIE \& BREDEMEIER; 2013; BUCCI et al., 2015; NAUBI et al., 2016).

As mudanças climáticas alteram a distribuição temporal das chuvas. A indisponibilidade de água em determinados períodos do ano demonstra irregularidades no ciclo pluviométrico; como consequência são observadas secas prolongadas ou períodos com enchentes (ARNELL \& GOSLING, 2013; ANA, 2015). Tal efeito tem deixado a população em situação de vulnerabilidade (IPCC, 2015). Contudo, a análise física e ambiental da bacia hidrográfica pode fornecer informações sobre a rede de drenagem, limites da bacia e detalhes da topografia, o que permite planejar medidas da conservação de água (PINTO et al., 2014; FARIAS et al., 2015; TANAKA et al., 2016).

Estudos morfométricos são essenciais na caracterização de bacias hidrográficas para a determinação de suas limitações e capacidades. Essas informações são necessárias para o planejamento e manejo das atividades desenvolvidas na região que circunda a área da bacia (SANTOS et al., 2012; SINGH et al., 2014; FARIAS et al., 2015). 
O Sistema de Informação Geográfica (SIG), de acordo com ELESBON et al. (2011), é de fundamental importância na caracterização automática da morfometria das bacias hidrográficas, pois possibilita a realização dos processos com maior eficiência e confiabilidade. Além disso, esse instrumento permite estudar as potencialidades de uma bacia hidrográfica, com 0 mapeamento de suas competências para planejamento futuro do uso e ocupação do solo (DA COSTA et al., 2003). Este trabalho teve como objetivo descrever as características morfométricas da bacia hidrográfica do Córrego Manhuaçuzinho e fornecer informações para o gerenciamento dos recursos hídricos.

\section{MATERIAL E MÉTODOS}

A Bacia Hidrográfica do Córrego Manhuaçuzinho está totalmente inserida no bioma Mata Atlântica do estado de Minas Gerais, nas regiões da Zona da Mata e Vale do Rio Doce integra, portanto, a macro bacia do Rio Doce (Figura 1). A bacia está localizada entre os paralelos N: 77758778,24 - 7774619,88 e meridianos E: 796594,92 - 803972,01, no município de Manhuaçu - MG. O clima é tropical de altitude, Cwa (Köppen), com precipitação anual média entre 1000 e 1500 mm.

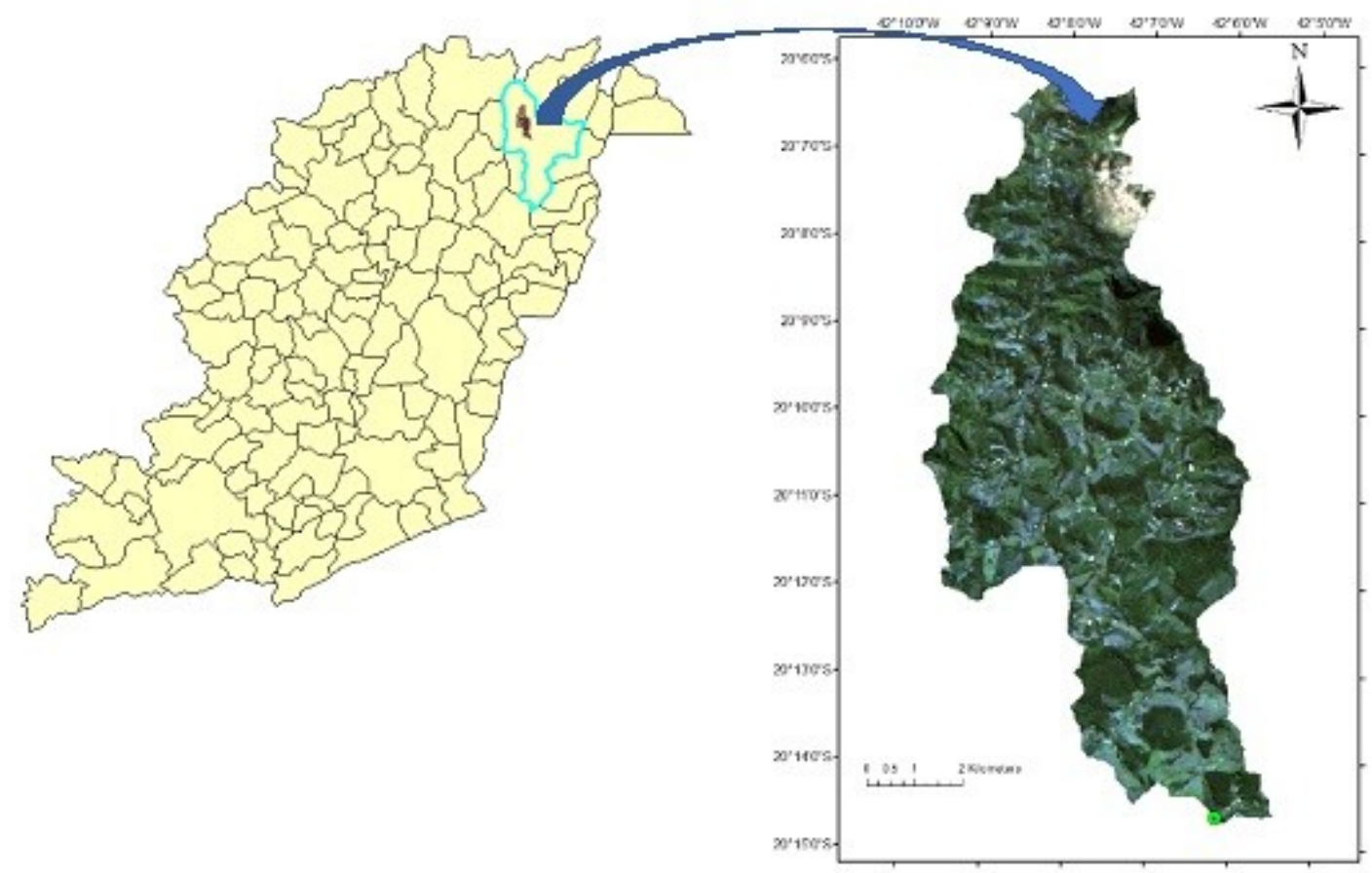

FIGURA 1 - Localização da Bacia Hidrográfica do Córrego Manhuaçuzinho, em Manhuaçu-MG. Fonte: IBGE, (2016).

Recentemente, a região passou por um longo período de secas, em que a precipitação ficou abaixo da média (Figura 2). No ano de 2014, ocorreu a situação mais crítica, dado o grande período de estiagem.

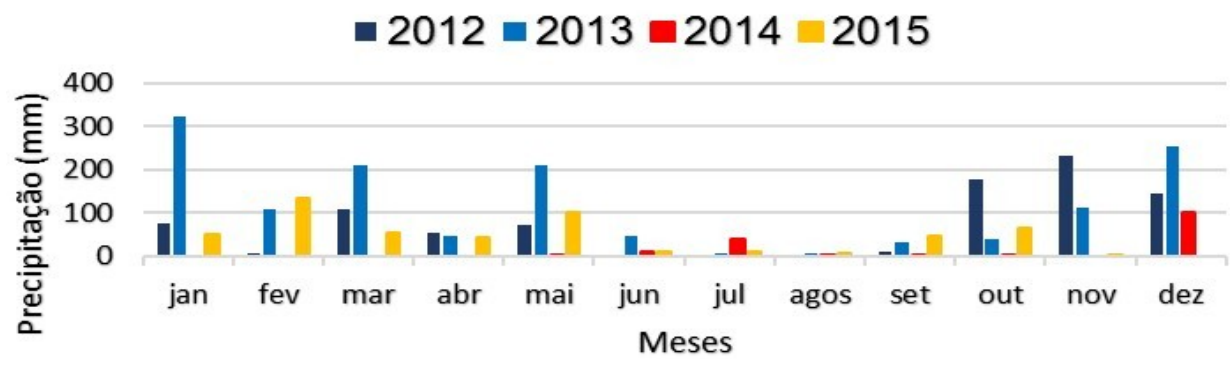

ENCICLOPÉDIA BIOSFERA, Centro Científico Conhecer - Goiânia, v.14 n.25; p.24 
FIGURA 2 - Distribuição mensal de precipitação para os anos de 2012-2015 na região da bacia do Córrego Manhuaçuzinho, Manhuaçu, MG. Fonte: INMET, (2016).

As classes de solos predominante nessa bacia são os Argissolos Vermelhos e os Latossolos Vermelho-Amarelo. Os Latossolos Vermelho-Amarelo são solos mais profundos, bem drenados e com horizonte $B$ latossólico de coloração vermelhoamarelo, presente, principalmente, em planaltos dissecados. Já os Argissolos Vermelhos caracterizam-se pela profundidade variável, com um horizonte subsuperficial com maior teor de argila, que pode determinar uma rápida saturação durante uma chuva forte. Dessa forma, reduz a capacidade de infiltração da água no solo (PARH - IGAM, 2010).

A pastagem com capim colonião nos solos eutróficos e o plantio de café, predominante nos vales, são as culturas mais relevantes no uso do solo da região. A principal limitação desses solos é o relevo.

\section{Uso de ferramentas para delimitar a bacia}

O software utilizado para delimitar a bacia em estudo foi o ArcGIS 10.3.1 (ESRI, 2015) e as cartas do IBGE (2016) foram referências para sua localização. A projeção adotada foi a UTM (Universal Transversa de Mercator) no fuso 23 Sul e Datum WGS (World Geodetic System) 84. Com a hidrografia previamente direcionada, os pontos de nascente e o ponto da foz georreferenciados, utilizaram-se na plataforma de operação do software as ferramentas fill para corrigir as depressões espúrias; a ferramenta flow direction para direcionar o fluxo da hidrografia; e, por fim, a ferramenta watershed para determinar a área de contribuição da bacia.

\section{Determinação dos parâmetros morfométricos}

Os parâmetros morfométricos da bacia hidrógrafica são divididos em três categorias:

- geométricos: avaliam a área e sua forma;

- relevo: designa o ordenamento, densidade de drenagem, declividade e altitude média da bacia;

- rede de drenagem: consiste nos padrões de drenagem, razão de bifurcação e orientação.

Alguns dos parâmetros utilizados na caracterização da bacia estão descritos no Quadro 1.

QUADRO 1 - Parâmetros utilizados para caracterização da bacia Manhuaçuzinho.

\begin{tabular}{ccc}
\hline Descrição & Fórmula & Referência \\
\hline Fator de forma & $F=\frac{A}{L^{2}}$ & HORTON, 1932 \\
Índice de circularidade & $I C=\frac{12,57 \cdot A}{P^{2}}$ & MILLER, 1953
\end{tabular}


Amplitude altimétrica

Declividade média

Relação de elongação

Coeficiente de compacidade

Razão de bifurcação

Densidade de drenagem

$$
H=e_{\max }-e_{\text {min }}
$$

$$
S \%=\frac{77 . L c}{P}
$$

SCHUMM, 1956

SCHUMM, 1956

HORTON, 1945

HORTON, 1945

HORTON, 1932

Fonte: elaborado pelos autores.

- fator de forma: relaciona a forma da bacia com a área de um retângulo, é determinado pela razão entre a área da bacia $(A)$ e comprimento do eixo da bacia (L) ao quadrado (HORTON, 1932);

- índice de circularidade: relaciona a área da bacia à área de um círculo de mesmo perímetro. O resultado desse parâmetro deve ser um valor menor ou igual a 1 (MILLER, 1953);

- amplitude altimétrica: é a relação das variações topográficas da bacia e corresponde à diferença altimétrica, em metros, entre a altitude da foz (elevação mínima) e a altitude do ponto mais alto no divisor topográfico (elevação máxima) próximo ao eixo (STRAHLER, 1952);

- declividade geral da bacia: a razão entre a amplitude altimétrica $(H)$ e 0 comprimento do eixo da bacia (L) (SCHUMM, 1956);

- relação de elongação: relaciona o diâmetro do círculo de mesma área da bacia (A) ao comprimento do eixo (L) (SCHUMM, 1956). Essa relação deve resultar em um valor menor ou igual a 1;

- coeficiente de compacidade: relaciona o perímetro da bacia $(P)$ a um perímetro de círculo de mesma área (HORTON, 1945). Esse coeficiente deve resultar num valor maior ou igual a 1 ;

- razão de bifurcação média: expressa a relação entre número de canais de uma certa ordem e o número de canais de uma ordem imediatamente superior (HORTON, 1945);

- densidade de drenagem: a proposta de HORTON (1932) correlaciona o comprimento total dos canais, em quilômetros, com a área da bacia hidrográfica, em quilômetros quadrados;

- orientação de fluxo: é a orientação do canal de maior comprimento da bacia, no sentido da foz.

Os valores máximo e mínimo de elevação foram obtidos por meio do Modelo Digital de Elevação (MDE) no ArcGIS. A área e o perímetro também são resultados provenientes da delimitação da bacia a partir do software. O ordenamento dos cursos d'água foi realizado segundo a metodologia de STRAHLER (1957).

\section{RESULTADOS E DISCUSSÃO}

O uso da ferramenta de Sistema de Informação Geográfica foi importante para extrair o Modelo Digital de Elevação Hidrograficamente Condicionado (MDEHC) da 
bacia Manhuaçuzinho. Com a bacia devidamente corrigida, calcularam-se os respectivos parâmetros (Tabela 1 ).

TABELA 1 - Parâmetros calculados da bacia através do MDEHC.

\begin{tabular}{cc}
\hline Parâmetros geométricos & Valor \\
Área & $61,50 \mathrm{~km}^{2}$ \\
Perímetro & $49,55 \mathrm{~km}$ \\
Eixo Perpendicular à bacia & $16,33 \mathrm{~km}$ \\
Comprimento do canal principal & $20,904 \mathrm{~km}$ \\
Elevação máxima & $1630,96 \mathrm{~m}$ \\
Elevação mínima & $731,38 \mathrm{~m}$ \\
Fator de forma & 0,23 \\
Coeficiente de Compacidade & 1,78 \\
\hline Índice de circularidade & 0,32 \\
Declividade média & $20,91 \%$ \\
Densidade de drenagem & 1,92 \\
Orientação de fluxo & $\mathrm{Sul}$ \\
\hline
\end{tabular}

Fonte: elaborado pelos autores.

De acordo com TUCCI (1997), se apenas a área da bacia for considerada, a chance de ocorrer enchentes é menor, quanto maior for a sua área. Isso acontece porque é difícil que incida uma grande contribuição de água em toda a bacia de uma só vez.

Com os dados obtidos do coeficiente de compacidade $(1,78)$, fator de forma $(0,2305)$ e índice de circularidade $(0,3148)$, pode-se concluir que a bacia de Manhuaçuzinho é alongada. Com base nessa classificação, é possível afirmar que ela apresenta uma menor concentração de deflúvio (VILLELA \& MATTOS, 1975). As bacias mais alongadas possuem baixas possibilidades de chuvas intensas ocorrerem em toda sua extensão simultaneamente (LORENZON et al., 2015). Contudo, a bacia de Manhuaçuzinho apresenta um menor risco de enchentes, apesar de ocupar uma área considerada pequena.

A forma da bacia hidrográfica influencia no tempo de concentração, que é o tempo necessário para que todo o armazenamento de água infiltre ou escoe após a precipitação. Nas bacias alongadas, como a deste estudo, os afluentes atingem o curso d'água principal em vários pontos no decorrer do fluxo. Já nas bacias circulares, a concentração do deflúvio ocorre em um só ponto, portanto, diminuem o tempo de concentração e aumentam as chances de ocorrência de enchentes (SINGH et al., 2014).

De acordo com TONELLO et al. (2006), quanto maior a ramificação da rede hidrográfica melhor será o sistema de drenagem. Com a análise do sistema de drenagem da bacia de Manhuaçuzinho (Tabela 2), observou-se que sua ordem é 5, segundo a classificação de STRAHLER (1957), e, por apresentar uma dimensão relativamente pequena, proporciona uma boa drenagem com suas ramificações e forma. De acordo com BHAGWAT et al. (2011), a razão de bifurcação controla a taxa de escoamento da bacia após uma forte chuva e com a média encontrada $(2,93)$, o risco de inundação é baixo.

TABELA 2 - Aspectos da ordem da Bacia Hidrográfica Córrego Manhuaçuzinho, em Manhuaçu, MG.

\begin{tabular}{cccc}
\hline $\begin{array}{c}\text { Ordem da } \\
\text { bacia }\end{array}$ & $\begin{array}{c}\text { Números de } \\
\text { canais }\end{array}$ & $\begin{array}{c}\text { Razão de } \\
\text { bifurcação }\end{array}$ & $\begin{array}{c}\text { Razão de bifurcação } \\
\text { média }\end{array}$ \\
\hline
\end{tabular}




\begin{tabular}{cccc}
\hline 1 & 86 & & 2,93 \\
2 & 18 & 4,77 & \\
3 & 5 & 3,6 & \\
4 & 2 & 2,5 & \\
5 & 1 & 1 & \\
Total & 159 & & \\
\hline
\end{tabular}

Fonte: elaborado pelos autores.

Diante da análise das ramificações encontradas, ou seja, com a configuração semelhante a uma árvore, típico de locais onde predominam rochas de resistência homogênea, pode-se inferir que o padrão de drenagem predominante é o dendrítico (Figura 3). Ao norte o afloramento de rochas é maior, portanto a bacia tende a ser retangular, onde as rochas mais resistentes definem o relevo.

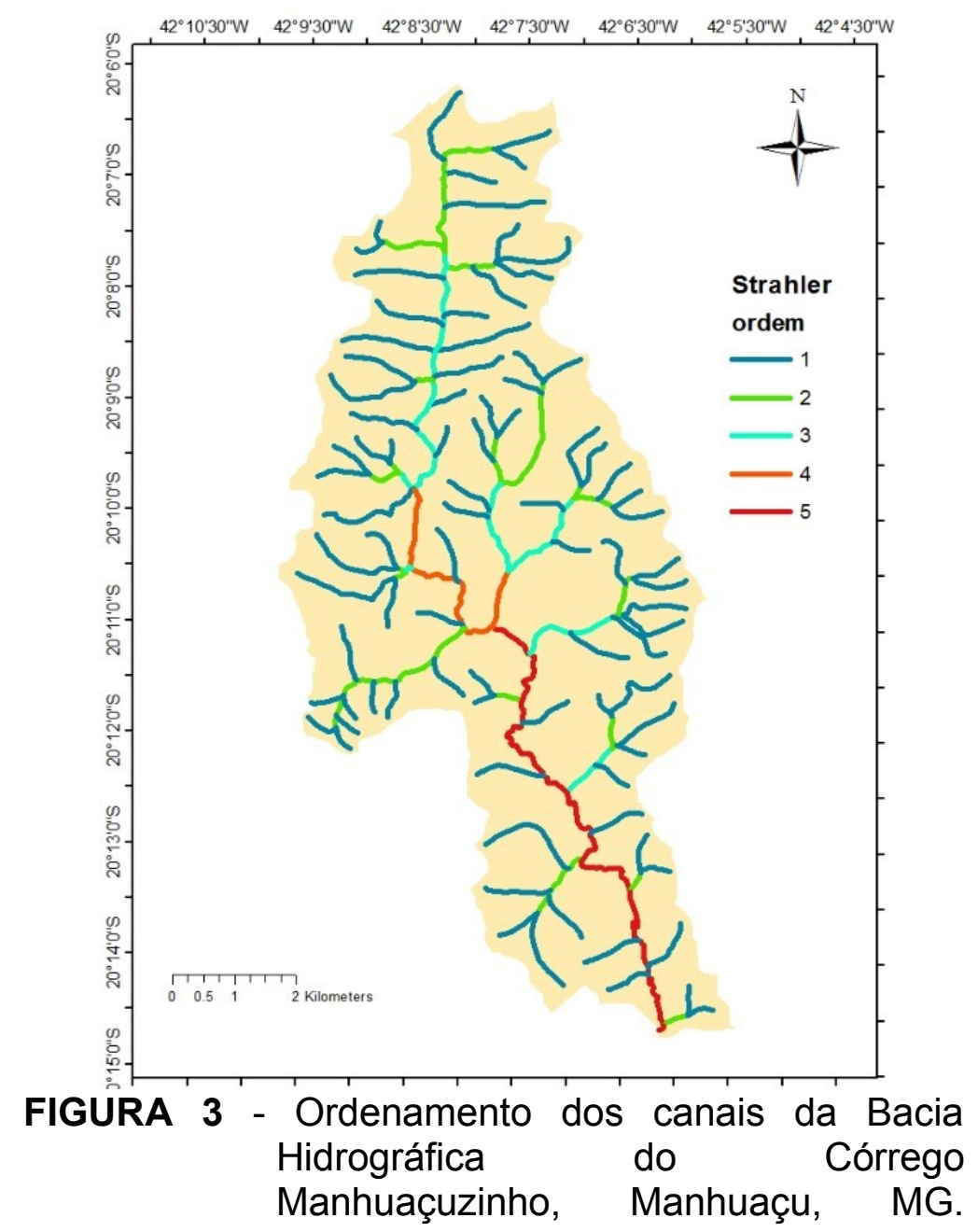

Fonte: elaborado pelos autores.

A região possui declividade média de $20,90 \%$, valor considerado alto segundo SCHUMM, 1956. O escoamento superficial possui efeito direto em áreas com elevada declividade, pois devido à velocidade de escoamento da água, sua infiltração no solo é reduzida (MARCHINI et al., 2015). LORENZON et al. (2015) avaliaram a influência da morfometria na incidência de enchentes em uma bacia em Alfredo Chaves-ES e observou que os distintos valores de declividade do rio principal e da bacia, são decorrentes da variação na altitude. 
A bacia do Córrego Manhuaçuzinho possui relevo predominantemente ondulado a fortemente montanhoso (Figura 4), além de apresentar eminente variação de altitude, com valores de 731 a $1630 \mathrm{~m}$. Essas diferenças altimétricas em uma bacia geram mudanças significativas na temperatura média, como consequência ocorrem variações na evapotranspiração e precipitação anual (SANTOS et al., 2012).

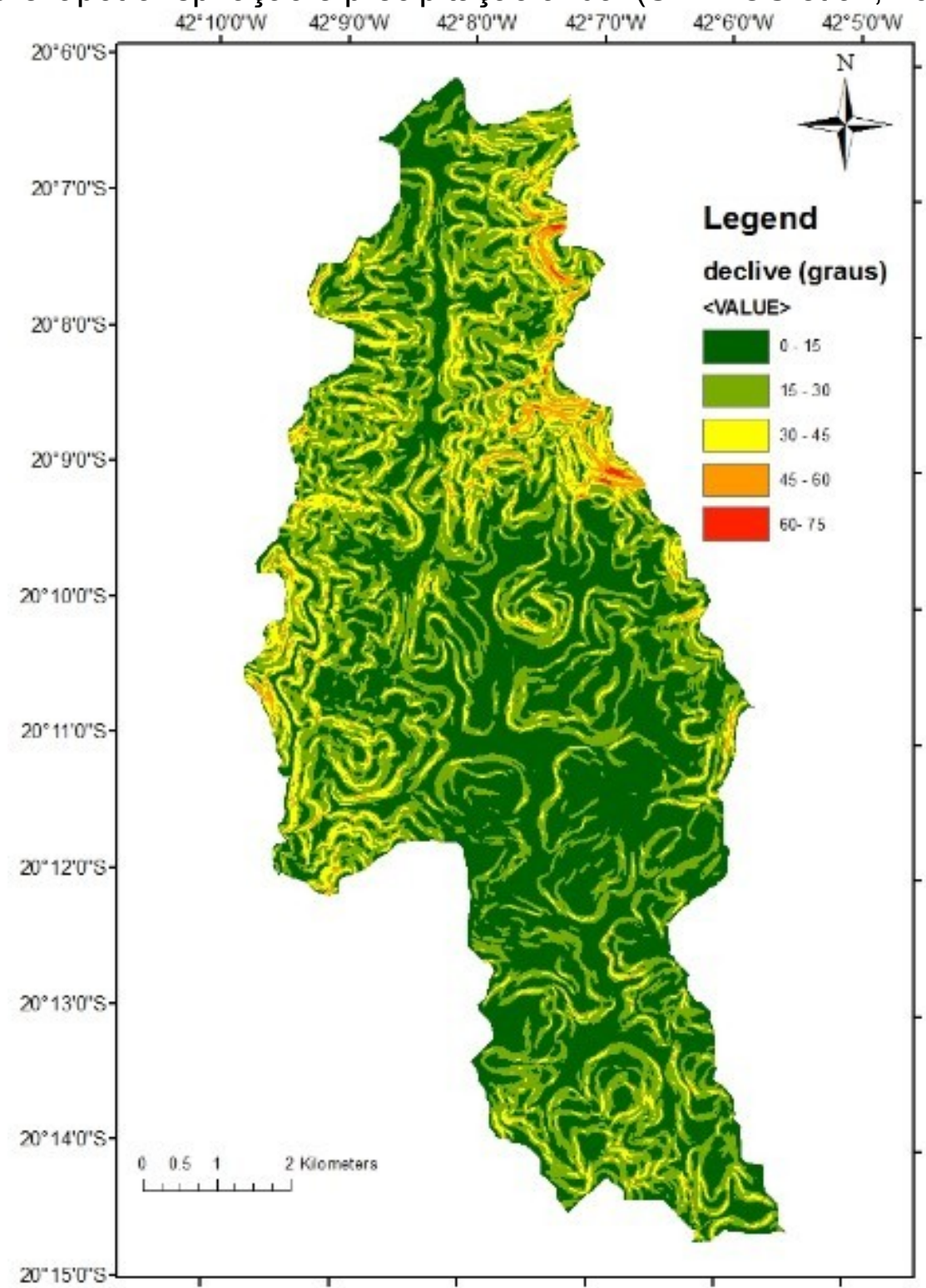

FIGURA 4 - Declividades da Bacia Hidrográfica do Córrego Manhuaçuzinho, Manhuaçu, MG. Fonte: elaborado pelos autores.

Como a bacia possui a maior parte de sua área em locais com declividade superior a 30 graus, ou seja, acima de $50 \%$ de inclinação, o relevo é classificado como montanhoso (Tabela 3).

TABELA 3 - Declividade da Bacia Hidrográfica do Córrego Manhuaçuzinho, Manhuaçu, MG.

\begin{tabular}{ccc}
\hline Declividade (graus) & Área $\left(\mathrm{Km}^{2}\right)$ & Área (\%) \\
\hline $0-15$ & 29,324 & 47,72 \\
$15-30$ & 22,649 & 36.86
\end{tabular}

ENCICLOPÉDIA BIOSFERA, Centro Científico Conhecer - Goiânia, v.14 n.25; p.29 
Fonte: elaborado pelos autores.

A densidade de drenagem é mediana $(1,92)$ de acordo com a classificação de HORTON (1945) e STRAHLER (1957). Esse fator influencia na geologia, topografia, e na velocidade escoamento da água da barragem. Dessa forma, apesar da bacia em estudo possuir relevo montanhoso, a presença de Latossolos altera o valor médio para densidade de drenagem, que se caracteriza por ser profundo e permeável e de alto intemperismo.

A bacia possui orientação para o sudeste, fato que caracteriza uma menor exposição solar ao longo do dia. A diminuição da evapotranspiração, aumenta a umidade do solo e a produção de água.

Recentemente, a região da bacia passou por um longo período de precipitações abaixo da média para o município $(1205 \mathrm{~mm})$. O primeiro ano desse período de estiagem foi registrado em 2012 e o último, e mais severo, em 2014 (Figura 2). Segundo a Agência Nacional de Águas (ANA) (2015), desde o ano de 2012 foi observado um comportamento pluviométrico bem abaixo do esperado no país, com seca extrema na região Sudeste do país. Dessa forma o deflúvio acentuado da bacia, associado ao baixo índice de chuvas e à ausência de práticas conservacionistas para o armazenamento de água, levaram à crise hídrica na cidade de Manhuaçu.

O uso do solo na região estudada caracteriza-se por pastagem, cafeicultura e plantios florestais. A pastagem, se bem conservada, é considerada uma das melhores coberturas para infiltração de água no solo. Porém em casos de degradação, favorece o escoamento superficial e interfere na vazão do curso de água. O cultivo do café caracteriza-se por ser a principal atividade da região, cujos plantios em nível favorecem os processos de infiltração. A presença de bovinos na área de estudo, degrada as pastagens e ocasiona o assoreamento da barragem de captação (Figura 5).

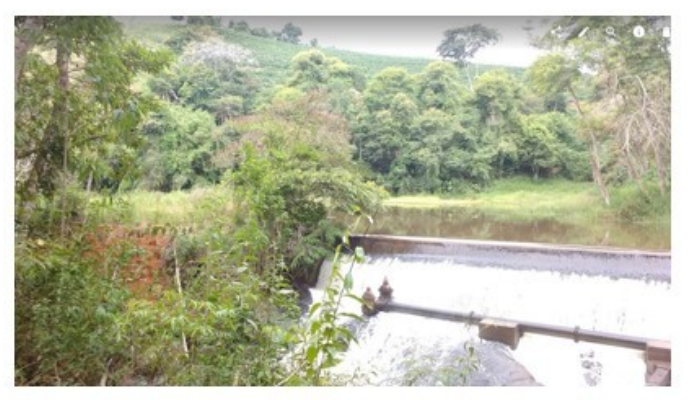

(a)

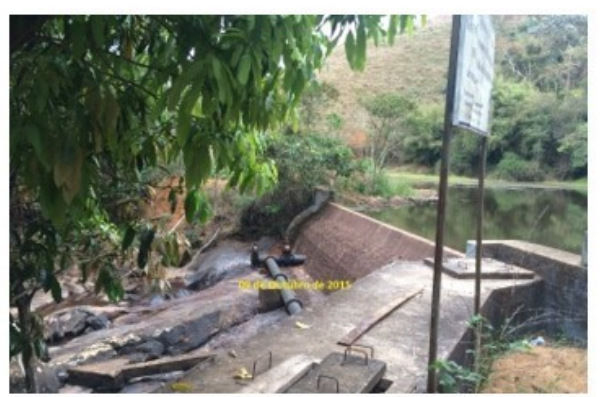

(b)

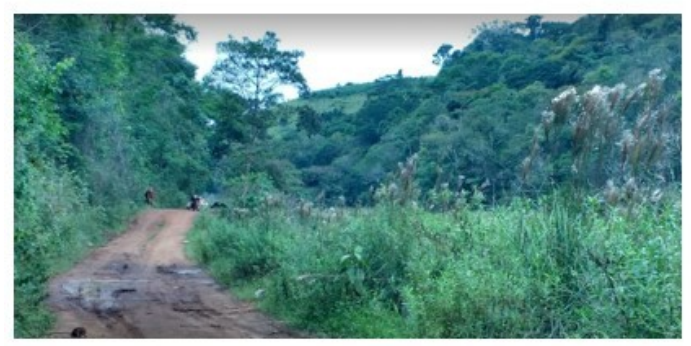

(c)

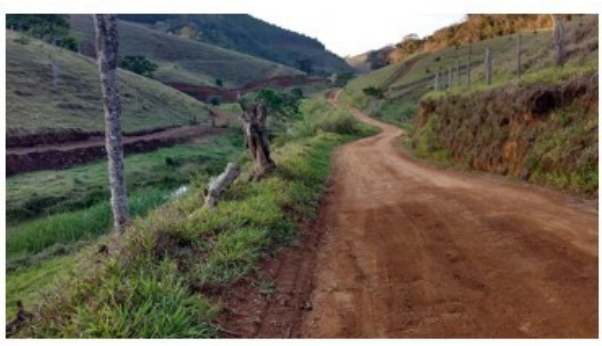

FIGURA 5 - (a) Barragem de captação para abastecimento urbano em fevereiro de 2016; (b) vazão em período crítico (outubro de 2015); (c) presença de 
bovinos próximos ao local; (d) ausência de vegetação nativa. Fonte: elaborado pelos autores.

\section{CONCLUSÃO}

O ambiente SIG foi de fundamental importância para realizar um diagnóstico dos parâmetros morfométricos da bacia de Manhuaçuzinho, pois com ele caracterizou-se os elementos sobre a rede de drenagem, definiram-se limites e detalhou-se a topografia. Dessa forma, possibilita o planejamento de medidas necessárias ao uso e à conservação da água.

É possível inferir, com base nos parâmetros, que a bacia possui características propícias para o armazenamento de água da barragem, visto que é alongada e possui orientação sudeste, ou seja, possui menor incidência solar e, consequentemente, a perda de água por evapotranspiração é menor. Embora a área da bacia seja considerada pequena, a sua forma dificulta a ocorrência de chuvas intensas em toda sua extensão, diminuindo, assim, o risco de enchentes.

$\mathrm{Na}$ análise de ramificações conclui-se que os canais de menor ordem são predominantes. O padrão da bacia é dendrítico de ordem 5 , com rochas de resistência homogênea. A razão média de bifurcação encontrada também permite inferir que o risco de inundação é baixo. A grande amplitude altimétrica influencia na temperatura média, que por sua vez, origina variações na evapotranspiração e na precipitação anual.

O relevo montanhoso favorece o escoamento superficial da água; dessa forma, são necessárias medidas que intensifiquem os processos de infiltração, o que pode ser feito por meio da construção de caixas de captação, terraços de base estreita, manutenção da vegetação nativa, delimitação de áreas de preservação permanente (APPs), a fim de impedir a entrada de gado no curso hídrico e favorecer a regeneração natural.

\section{REFERÊNCIAS}

AGÊNCIA NACIONAL DE ÁGUAS (ANA). Encarte especial sobre a crise hídrica. Conjuntura dos recursos hídricos no Brasil (Informe 2014). 2015.

ARNELL, N. W.; GOSLING, S. N. The impacts of climate change on river flow regimes at the global scale. Journal of Hydrology, v.486, p.351-364, 2013. Disponível em: <http://dx.doi.org/10.1016/j.jhydrol.2013.02.010>. doi: 10.1016/j.jhydrol.2013.02.010.

BERTOL, I.; BARBOSA, F. T.; BERTOL, C.; LUCIANO, R. V. Water infiltration in two cultivated soils in Southern Brazil. Revista Brasileira de Ciência do Solo, v.39, n.2, p.573-588, 2015.2 Disponível em: <http://dx.doi.org/10.1590/01000683rbcs20140304>. doi: 10.1590/01000683rbcs20140304.

BERTOSSI, A. P. A.; JÚNIOR, P. P. R.; RIBEIRO, P. H.; MENEZES, J. P. C.; CECÍLIO, R. A.; ANDRADE, F. V. Soil cover and chemical and physical atributes in oxisol in the atlantic forest biome. Revista Árvore, v.40, n.2, p.219-228, 2016. 
Disponível em: <http://dx.doi.org/10.1590/0100-67622016000200004>. doi: 10.1590/0100-67622016000200004.

BHAGWAT, T. N.; SHETTY, A.; HEGDE, V. S. Spatial variation in drainage characteristics and geomorphic instantaneous unit hydrograph (GIUH); implications for watershed management - A case study of the Varada River basin, Nothern Karnataka. Catena, v.87, n.1, p.52-59, 2011. Disponível em: <http://dx.doi.org/10.1016/j.catena.2011.05.007>. doi: 10.1016/j.catena.2011.05.007.

BUCCI, M. M. H. S.; DELGADO, F. E. F.; OLIVEIRA, L. F. C. Water quality and trophic state of a tropical urban reservoir for drinking water supply (Juiz de Fora, Brazil). Lake and Reservoir Management, v.31, n.2, p.134-144, 2015. Disponível em: <http://dx.doi.org/10.1080/10402381.2015.1029151>. doi: 10.1080/10402381.2015.1029151.

DA COSTA, L. A.; SOARES, V. P; RIBEIRO, C. A. A. S.; SILVA, H.; ANTUNES, M. A. H.; HOTT, M. C. Determinação da aptidão florestal de uma microbacia por meio de um sistema de informações geográficas. Revista Ceres, v.50, n.288, p. 219-239, 2003. Disponível em: <http://dx.doi.org/10.4322/floram.2013.023>. doi: 10.4322/floram.2013.023.

DESSIE, A.; BREDEMEIER, M. The effect of deforestation on water quality: A case study in Cienda micro watershed, Leyte, Philippines. Resources and Environment, v.3, n.1, p.1-9, 2013. Disponível em: <http://dx.doi.org/10.5923/j.re.20130301.01>. doi: 10.5923/j.re.20130301.01.

DIAS, L. C. P.; PIMENTA, F. M.; SANTOS, A. B.; COSTA, M. H.; LADLE, R. J. Patterns of land use, extensification, and intensification of Brazilian agriculture. Global Change Biology, v.22, n.8, p.2887-2903, 2016. Disponível em: <http://dx.doi.org/10.1111/gcb.13314>. doi: 10.1111/gcb.13314.

ESRI - Environmental Systems Research Institute, Inc. ArcGIS Professional GIS for the desktop, versão 10.3.1. CA. 2015.

FARIAS, R. N.; PEDROZO, C. S.; MACHADO, N. A. F.; RODRIGUEZ, M. R. Análise morfométrica e de usos do solo da bacia hidrográfica do Arroio Candiota, RS, Brasil. Pesquisas em Geociências, v.42, n.2, p.159-172, 2015. Disponível em: <http://dx.doi.org/10183/104798/000930767>. doi: 10183/104798/000930767.

HORTON, R. E. Drainage basin characteristics. American Geophysical Union, v.13, n.1, p.350-361, $1932 . \quad$ Disponível em: <http://dx.doi.org/10.1029/TR013i001p00350>. doi: 10.1029/TR013i001p00350.

HORTON, R. E. Erosional development of streams and their drainage basins, hydrophysical approach to quantitative morphology. The Geological Society of America, v.56, n.2, p.275-370, 1945. Disponível em: <http://dx.doi.org/10.1177/030913339501900406>. doi: 10.1177/030913339501900406. 
IBGE, Instituto Brasileiro de Geografia e Estatística. Bases e referências: bases cartográficas. Disponível em: <http://mapas.ibge.gov.br/bases-e-referenciais/basescartograficas/cartas>. Acesso em: 01 nov. 2016.

INMET, Instituto Nacional de Meteorologia. Estações automáticas. Disponível em: $<$ http://www.inmet.gov.br/portal/index.php?

$r=$ home/page\&page=rede_estacoes_auto_graf $>$. Acesso em: 01 nov. 2016.

IPCC, Intergovernmental Panel on Climate Change. Climate Change 2014: Impacts, Adaptation, and Vulnerability. United Kingsom; New York: Cambridge, 2015. 1132p.

LORENZON, A. S.; DIAS, H. C.; TONELLO, K. C. Escoamento superficial da agua da chuva em um fragmento florestal de Mata Atlântica, Viçosa-MG. Revista Brasileira de Agropecuária Sustentável, v.5, n.1, p.50-58, 2015. Disponível em: <http://dx.doi.org/10.21206/rbas.v5i1.316>. doi: 10.21206/rbas.v5i1.316.

MARCHINI, D.; LING, T. C.; ALVES, M. C.; CRESTANA, S.; FILHO, S. N. S.; ARRUDA, O. G. Matéria orgânica, infiltração e imagens tomográficas de Latossolo em recuperação sob diferentes tipos de manejo. Revista Brasileira de Engenharia Agrícola e Ambiental, v.19, n.6, p.574-580, 2015. Disponível em: <http://dx.doi.org/10.1590/1807-1929/agriambi.v19n6p574-580>. doi: 10.1590/18071929/agriambi.v19n6p574-580.

MILLER, V. C. A quantitative geomorphic study of drainage basin characteristics in the Clinch Mountain area, Virginia and Tennessee. The Journal of Geology, v.65, n.1, p.389-042, 1953. Disponível em: <http://dx.doi.org/10.1086/626413>. doi: $10.1086 / 626413$.

NAUBI, I.; ZARDARI, N. H.; SHIRAZI, S. M.; IBRAHIM, N. F. B.; BALOO, L. Effectiveness of water quality index for monitoring Malasian river water quality. Polish Journal of Environmental Studies, v.25, n.1, p.231-239 2016. Disponível em: <http://dx.doi.org/10.15244/pjoes/60109>. doi: 10.15244/pjoes/60109.

PARH - IGAM. Plano de Ação de Recursos Hídricos da Unidade de Planejamento e Gestão dos Recursos Hídricos. Consórcio Ecoplan - Lume. 2010.

PINTO, V. G.; LIMA, R. N. S.; RIBEIRO, C. B. M.; MACHADO, P. J. O. Diagnóstico físico-ambiental como subsídio a identificação de áreas vulneráveis à erosão na bacia hidrográfica do Ribeirão do Espírito Santo, Juiz de Fora (MG), Brasil. Revista Ambiente e Água, v.9, n.4, p. 632-646, 2014. Disponível em: <http://dx.doi.org/10.4136/ambi-agua.1416>. doi: 10.4136/ambi-agua.1416.

RAMOS, J. C.; BERTOL, I. BARBOSA, F. T.; MARIOTI, J. WERNER, R. S.; BORGES, J.P. Influência das condições de superfície e do cultivo do solo na erosão hídrica em um Cambissolo Húmico. Revista Brasileira de Ciência do Solo, v.38, n.5, 2014. Disponível em: <http://dx.doi.org/10.1590/S0100-06832014000500024>. doi: 10.1590/S0100-06832014000500024. 
SANTOS, A. M.; TARGA, M. S.; BATISTA, G. T.; NELSON, W. D. Análise morfométrica das sub-bacias hidrográficas Perdizes e Fojo no município de Campos do Jordão, SP, Brasil. Revista Ambiente e Água, v.7, n.3, 2012. Disponível em: <http://dx.doi.org/10.4136/ambi-agua.945>. doi:10.4136/ambi-agua.945.

SCHUMM, S.A. Evolution of drainage systems and slopes in badlands at Perth, Amboy, New Jersey. The Geological Society of America, v.67, n.5, p.597-646, 1956. Disponível em: <http://dx.doi.org/10.1130/00167606(1956)67[597:EODSAS]2.0.CO;2>. doi: 10.1130/00167606(1956)67[597:EODSAS]2.0.CO;2.

SINGH, P.; GRUPTA, A.; SINGH, M. Hydrological inferences from watershed analysis for water resource management using remote and GIS tecniques. The Egyptian Journal of Remote Sensing and Space Sensing, v.17, n.2, p.111-121, 2014. Disponível em: <http://dx.doi.org/10.1016/j.ejrs.2014.09.003>. doi: 10.1016/j.ejrs.2014.09.003.

STRAHLER, A. N. Hypsometric Analysis of Erosional Topography. The Geological Society of America, v.63, n.11, p.1117-1142, 1952. Disponível em: <http://dx.doi.org/10.1130/0016-7606(1952)63[1117:HAAOET]2.0.CO;2>. doi: 10.1130/0016-7606(1952)63[1117:HAAOET]2.0.CO;2.

STRAHLER, A. N. Quantitative analysis of watershed geomorphology. American Geophysical Union, v.38, n.6, p.913-920, 1957. Disponível em: <http://dx.doi.org/10.1029/TR038i006p00913>. doi: 10.1029/TR038i006p00913.

TANAKA, M. O.; SOUZA, A. L. T. ; MOSCHINI, L. E. ; OLIVEIRA, A. K. Influence of watershed land use and riparian characteristics on biological indicators of stream water quality in southeastern Brazil. Agriculture, Ecosystems \& Environment, v. 216, p.333-339, 2016. Disponível em: <http://dx.doi.org/10.1016/j.agee.2015.10.016>. doi: 10.1016/j.agee.2015.10.016.

TONELLO, K. C.; DIAS, H. C. T.; DE SOUZA, A. L.; RIBEIRO, C. A. A. S.; LEITE, F. P. Morfometria da bacia hidrográfica da Cachoeira das Pombas, Guanhães - MG. Revista Árvore, Viçosa, v.30, n.5, p.849-857, 2006. Disponível em: <http://dx.doi.org/10.1590/S0100-67622006000500019>. doi: 10.1590/S010067622006000500019.

TUCCI, C. E. M. Hidrologia: ciência e aplicação. Coleção ABRH de Recursos Hídricos, Porto Alegre, v.4, n.2, 1997. 943p.

VILLELA, S. M.; MATTOS, A. Hidrologia aplicada. São Paulo: McGraw-Hill do Brasil, 1975. 245p. 